\title{
Bosnian Chardaklia House: The Dzider Family's House in The Crnoc Village near Kakanj
}

\author{
Ahmet Hadrović ${ }^{*}$ \\ Faculty of Architecture, University of Sarajevo, Sarajevo, Bosnia and Hercegovina
}

\author{
Citation: Hadrović A. Bosnian Chardaklia House: The Dzider \\ Family's House in The Crnoc Village near Kakanj. SEE J Arch

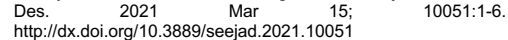 \\ Key words: Dzider family; Crnoc village; Chardaclia; \\ Bioclimatic architecture \\ 'Correspondence: Prof. Dr. Ahmet Hadrović, Faculty of \\ Architecture, University of Sarajevo, Sarajevo, Bosnia and \\ Hercegovina. E-mail: ahmeth@af.unsa.ba \\ Received: 06-Oct-2020; Revised: 20-Feb-2021; Accepted: \\ 26-Feb-2021; Published: 15-Mar-2021 \\ Copyright: ๑ 2021 Ahmet Hadrović. This is an open-access \\ article distributed under the terms of the Creative Commons \\ Attribution License, which permits unrestricted use, distribution, \\ and reproduction in any medium, provided the original author \\ and source are credited. \\ Competing Interests: The author have declared that no
} competing interests exist.

\begin{abstract}
The Dzider family's house in the Crnoc village near Kakanj is located on the flat terrain of a steep slope with southwestern insolation. It is one of a large number of relatively preserved bosnian chardaklia houses in the area of Kakanj, in the territory of Bosnia and Herzegovina where the most developed types of Bosnian chardaklia house were built.

The house was built during the reign of the Ottoman Empire (before the 19th century), but to date it has undergone a number of reconstructions and renovations. It belongs to the type of two-tracts bosnian chardaklija house. One of the most valuable features of this house (except for its age) is the fact that it was erected on a living water source, which is still in the basement of the house today.
\end{abstract}

\section{Introduction}

The Bosnian chardaklia house is one of the most authentic and representative examples of traditional architecture of Bosnia and Herzegovina, reflecting the complex natural and social environment of that person with its architectural and spatial solutions, construction and materialization, flexibility, and openness for longterm use (once and through four generations), both the client and its immediate creator. It is the home of wealthy people who live in the countryside but are firmly attached to the city with their jobs and overall lifestyles.
Unlike the oriental-type city house in Bosnia and Herzegovina (Hadrovic, 2007), which, due to the fact that it is a "city", was exposed to socio - cultural influences by other (oriental) civilizations, the bosnian chardaklia house is an expression of an authentic natural and social environment of Bosnia and Herzegovina. As Bosnia and Herzegovina is a complex multireligious, multiethnic and multicultural society, the bosnian chardaklia house emerges as a common denominator for all these differences, often to such an extent that one does not notice from which of these identities the house in question belongs. Valuable examples of this house can be found in the three largest ethnic groups - Muslims (Bosniaks), Catholics 
(Croats) and Orthodox (Serbs).

The bosnian chardaklia house evolved from the house of cattle men, that is, from the dwellings of seasonal mountain settlements (katuns) which can more or less (today) be found on the mountains of the Dinaric massif (Bosnia and Herzegovina, Serbia, Montenegro). One of the basic features of the Bosnian chardaklia house is its spatial development vertically, in the basementground floor-first floor (čardaci) scheme.

In addition to this fundamental feature, over time, several types of bosnian chardaklia house became known, which can be linked to the specificity of the natural and social environment of Bosnia and Herzegovina (Hadrovic, 2017):

a) Two-tracts (2 Tr),

b) Three-tracts houses ( $3 \mathrm{Tr}$ ),

c) Central House Solution (CHS).

\section{Location and Context}

The Dzider family's house in the Crnoc village near Kakanj is located on the flat terrain of a steep slope with southwestern insolation (Figure 1).

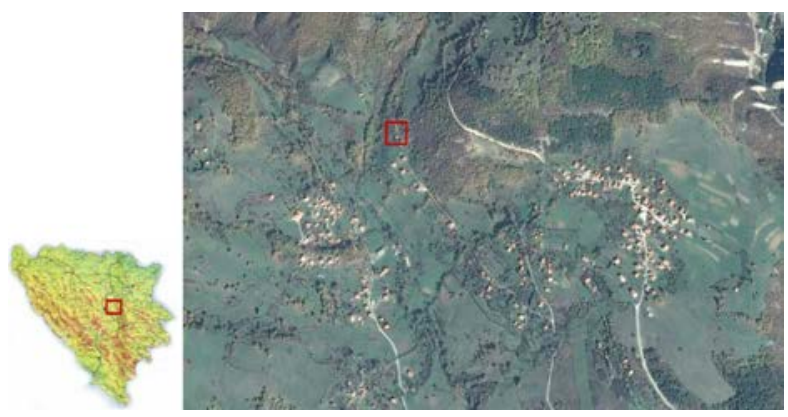

Figure 1: Dzider family house in the Crnoc village near Kakan; Location (Geographical coordinates: 44 09 '45.27" N; 18 07' 51.21" E; Elevation: 582 m. Source: Google Earth. Accessed: 03/01/2020

It is one of many relatively preserved bosnian chardaklia houses around Kakanj, in the territory of Bosnia and Herzegovina where the most developed types of Bosnian chardaklia house were built (Figure 2).

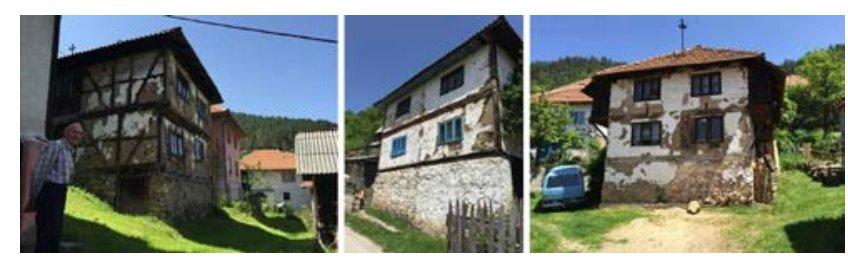

Figure 2: Bosnian chardaklia house in Kakanj area; Left - in the Starposle village; Center and right - in the Brnjic village

The house was built during the reign of the Ottoman Empire (before the 19th century), but to date it has undergone a number of reconstructions and renovations. It belongs to the type of two-tracts bosnian chardaklija house. One of the most valuable features of this house (except for its age) is the fact that it was erected on a living water source, which is still in the basement of the house today.

\section{Spatial - shape characteristics of the house}

According to the layout of the horizontal plans, Dzider family's house in the Crnoc village near Kakanj belongs to the type of two-tracts bosnian chardaklia house, which was developed vertically through the basement, ground floor and first floor (Figure 3).

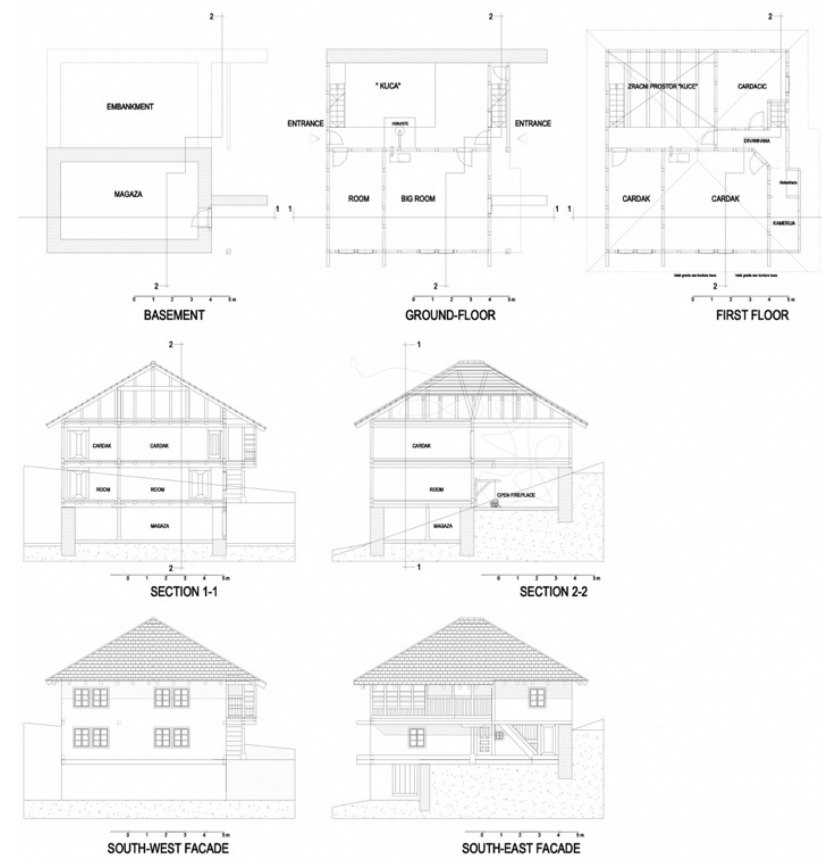

Figure 3: Dzider family's house in the Crnoc village near Kakanj; Disposition

The basement is arranged just below one ground floor tract. It is the main pantry of a household where more durable foods are stored.

The ground floor is accessed from the porch area on the southeast side of the house, into the "house" (kuća) space with an open hearth (Figure 3 and Figure 4).
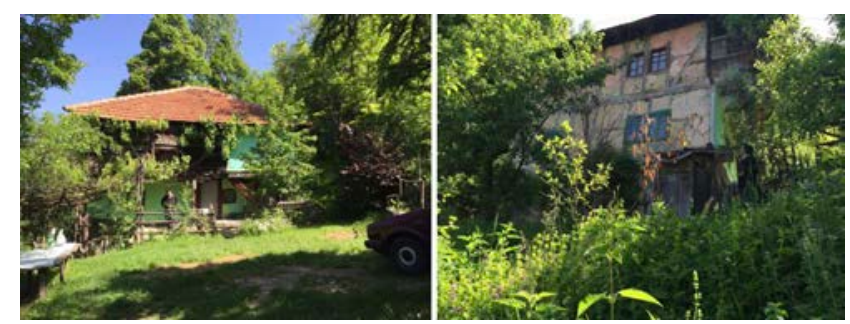

Figure 4: Dzider family's house in the Crnoc village near Kakanj

The second entrance (on the northwest side of the house) is still preserved today, but the porch adjacent to that entrance has been removed (since it has ceased to be used over time), (Figure 5). 

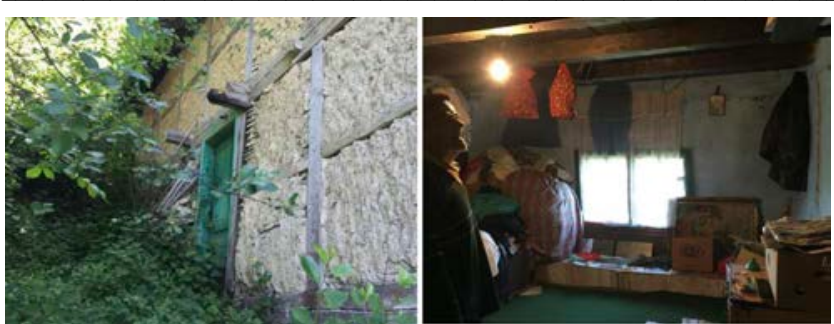

Figure 5: Left - entrance to the "house" ("kuća") space on its northwest side (It may be that there used to be a porch); Right - a small room downstairs

Although several reconstructions were made on the building, the area of the "house“ (kuća) with a hearth has remained preserved to this day (Figure 6 , and Figure 7).

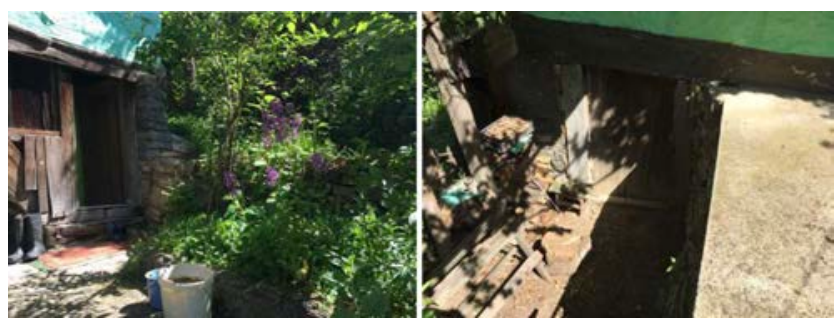

Figure 6: Left - ground floor entrance and access to the first-floor staircase; Right - the space in front of the store

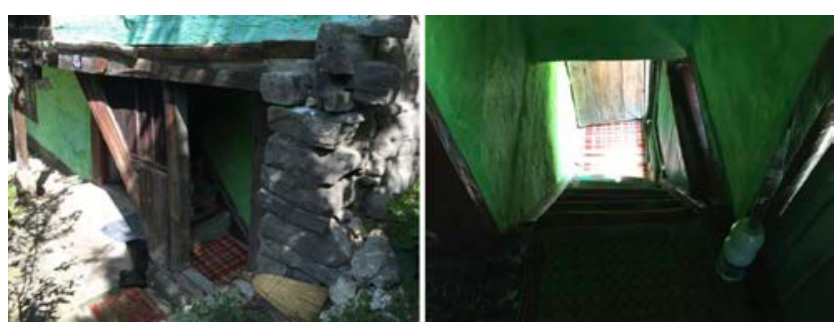

Figure 7: Access staircase for divanhana (upstairs)

From the "house" (kuća) space is accessed two rooms that are arranged above the basement space (Figure 8).
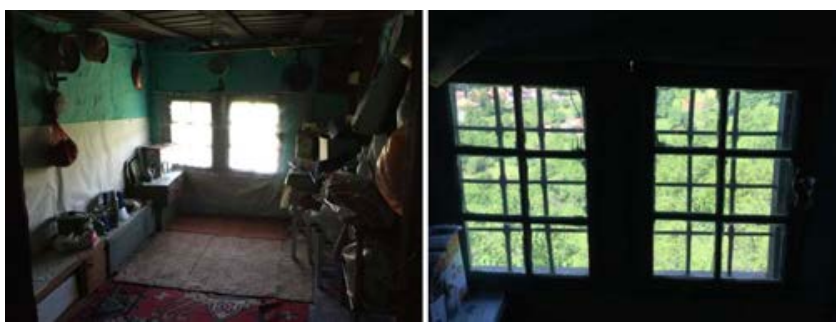

Figure 8: Left - space of a small chardak accessed from the gallery; Right - view from a window of a small chardak to the surroundings of the house

A one-pointed wooden staircase, located in a corner, along the northwest wall, connects the space of the "house“ (kuća) with the upstairs rooms (Figure 9).

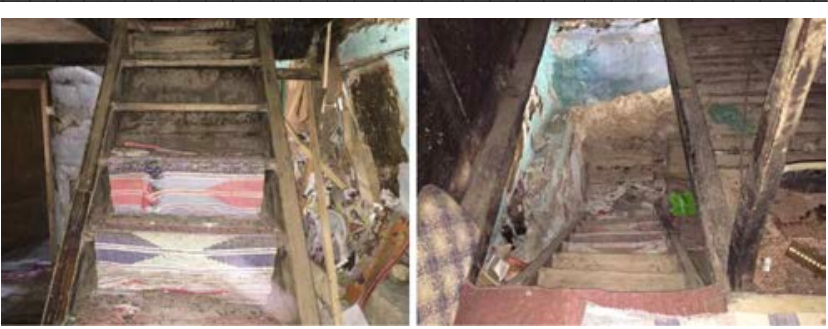

Figure 9: Staircase in the space of the "house" (kuća) that leads to the gallery

The first floor of the house is mostly accessed by a staircase on the southeast side of the house (Figure 3, Figure 4, and Figure 7). This staircase first approaches the divanhana space, which has an enlarged and formally accentuated part - „Kamerija“ (Figure 10).

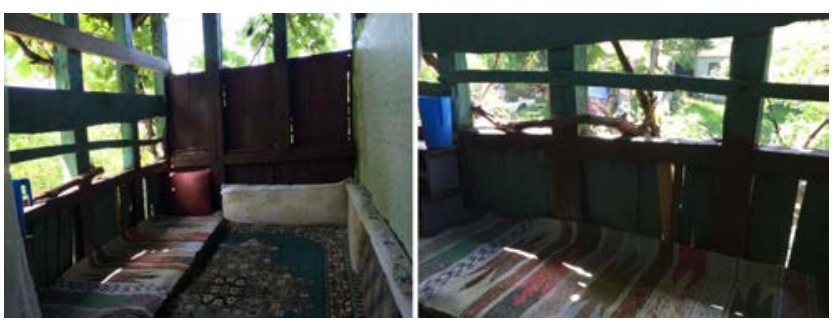

Figure 10: Kamerija (extended place at divanhana)

The „Kamerija“ is enriched by the interlacing of the vines planted in the courtyard (Figure 11).

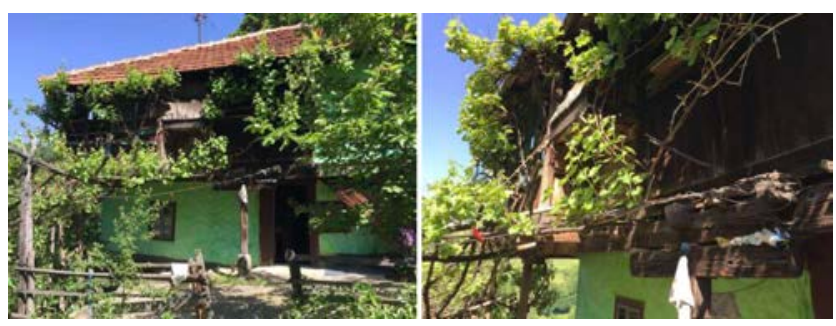

Figure 11: "Kamerija" - nature house and nature in the house

In the divanhana space is also a niche, abdesthana, which in the original design of the house was a place for prayer (abdest), (Figure 12).
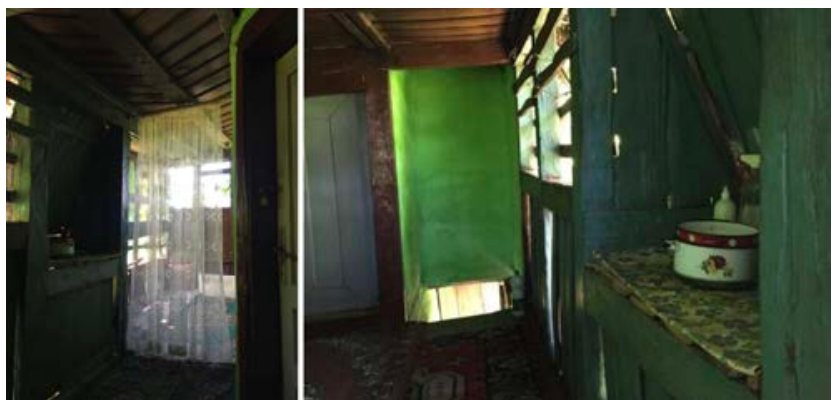

Figure 12: Left - divanhana space with abdesthana (now tea-kitchen); Right - abdesthana (now tea-kitchen) 
Today, abdesthana is decorated in a convenience kitchen with a Kamerija". From the divanhana it is directly accessed in two chardaks, one above the "house" (kuća) space, the other above the ground floor room and into the narrow hallway leading to the gallery in the "house" airspace (Figure 13).
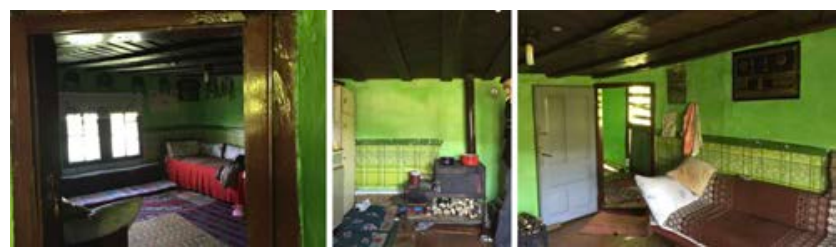

Figure 13: Arrangement of a large chardak

This gallery is, as already mentioned, accessed by an internal staircase from the space of the "house" and from the gallery into a small chardak (Figure 8). The gallery shows the space of the "house“ and the garret above the open hearth (Figure 3 and Figure 9).

\section{Construction and Materialization}

The structure of the Dzider family's house in the Crnoc village near Kakanj is typical the Bosnian chardaklia house. The basement walls are made of finely worked stone (80 cm thick), (Figure 14, left and Figure 15, left).

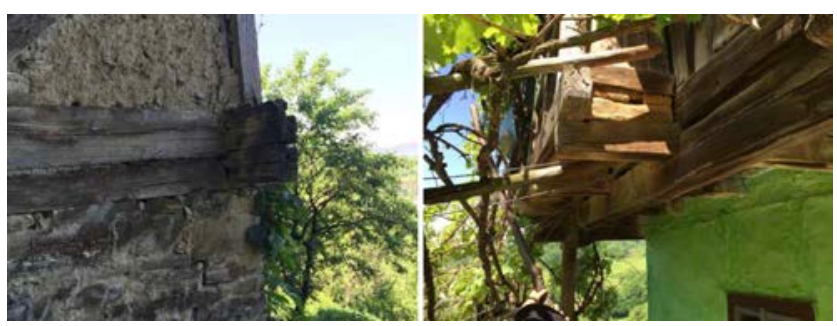

Figure 14: Details of authentic construction and materialization

The floor construction was done in a wooden bonduce with a fill of adobe - blocs (ćerpič) and a piece of wooden wicker with packed earth, (Figure 15, right).
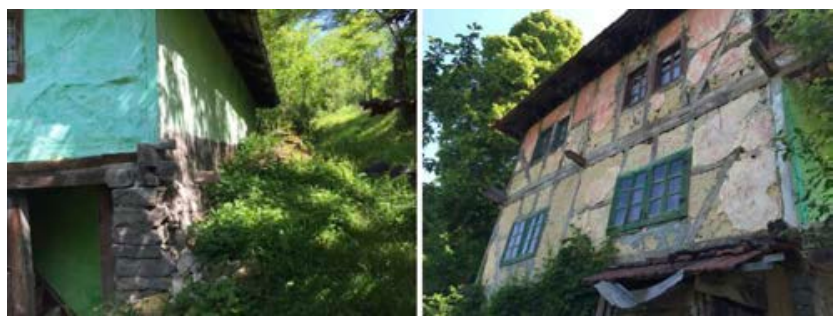

Figure 15: Construction and materialization; Left - the perimeter walls of the basement; Right - bondruk ground and first floor construction

The original roof structure has been reconstructed so that the new roof has a small slope (about $30^{\circ}$ ), covered with tiles. The construction between floors on all levels are made of wooden beams with solid wooden floors (Figure 16 and Figure 17).

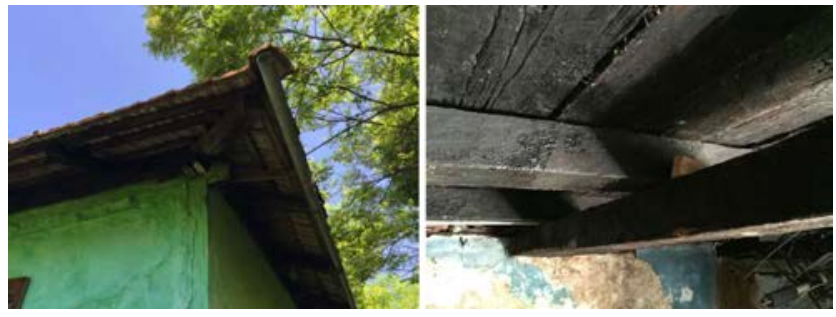

Figure 16: Left - detail of the roof eaves; Right - ground floor/first floor (gallery) structure viewed from the "house" ("kuća") space

The basement-ground and ground floor-first floor ceilings are simple: on the wooden beams, on their upper side, is placed below the floors above, which is the only border between the two spaces (Figure 16 - right, Figure 17, and Figure 18 - left).
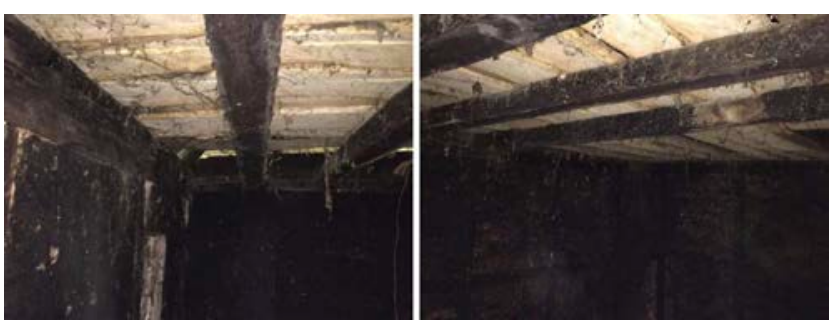

Figure 17: Authentic wooden beams in the airspace of the "house" ("kuća") toward the garret; New boards were later installed after ceasing to use open hearth

The structure between first floor towards the garret is more complex: on the upper side of the beam is a ceiling of thick wooden planks, and at a certain height of the beam is the ceiling of the chardak made of finely treated wooden planks ("šiše"). Between the garret floor and the chardak ceiling, a layer of packed soil with straw and chaff washes was inserted, which had the function of thermal insulation (Figure 18, right).
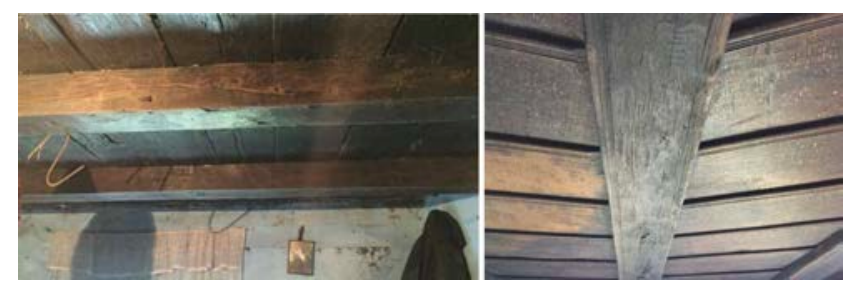

Figure 18: Left - wooden ceiling in the room above the storeroom; Right - a wooden ceiling in the chardak accessed from the gallery

\section{Doors and Windows}

Some doors have been preserved in their original design (Figure 19, Figure 20 - left, and Figure 21 ), while others have been designed in the 1950s as a replacement for the original door (Figure 20, right). 


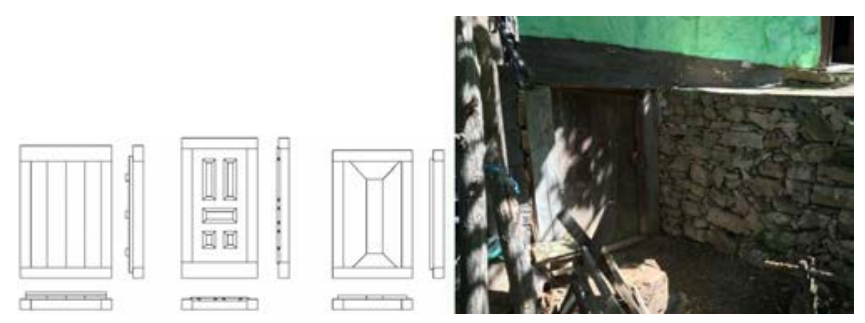

Figure 19: Left - different door design solutions; Right - authentic storeroom door

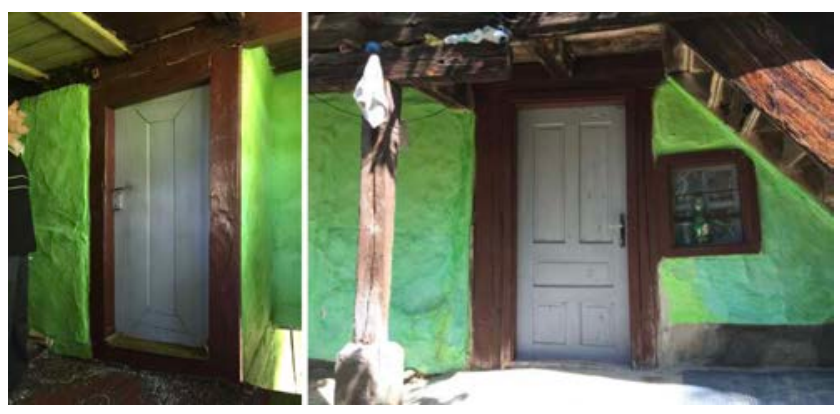

Figure 20: Left - authentic door design on the chardak (above part of the "house" space); Right - front door to the "house" area (mid-20th century design)

Some doors retained the "patina of time", a specific honey color created by the permanent smoke from an open hearth in the space of the "house" (Figure 21 , middle and right).

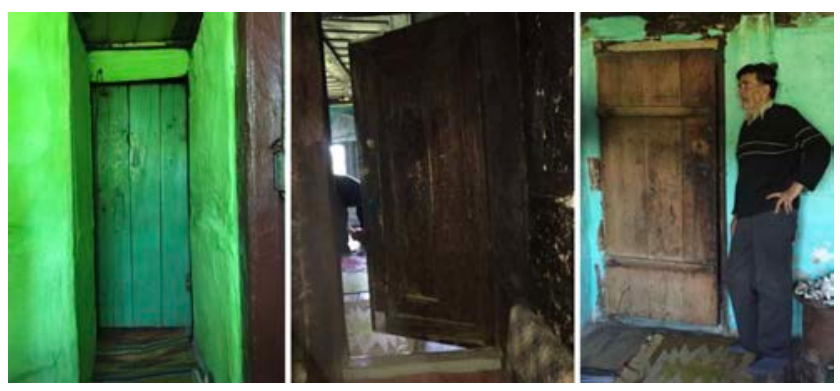

Figure 21: Left - gallery access door from divanhana space; In the middle and right - an authentic door on the chardak accessed from the gallery

Newer design doors as well as some original design doors are painted (Figure 20, and 21, left).

All the windows on the house are preserved in their original design. Wooden window frames ("window boxes") are widths that follow the thickness of the walls (Figure 22).
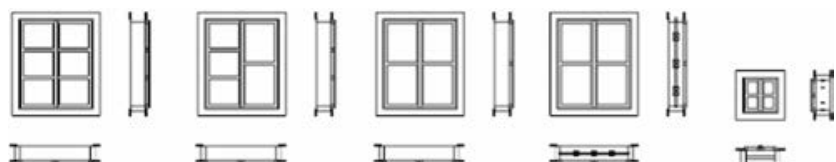

Figure 22. Window design gallery

The wings (single windows) are placed in the plane of the outer surface of the wall where the frames are edged with wooden planks ("pervazovi"), (Figure 23).

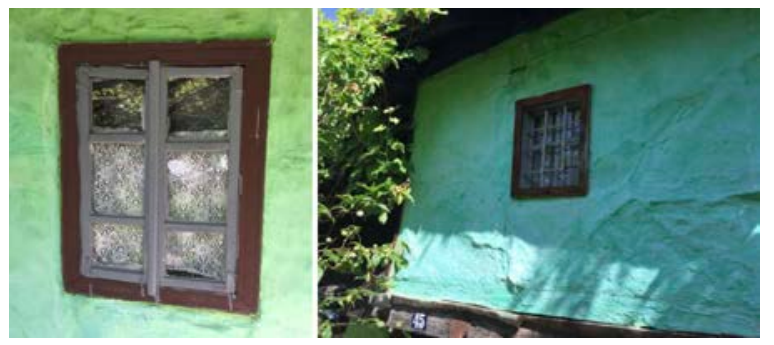

Figure 23. Left - authentic window in the "house" space oriented to the entrance porch with a staircase. Right - authentic window on the home yard ("avlija")

An interesting solution is the "double" windows on the rooms and the chardaks above them (Figure 24).

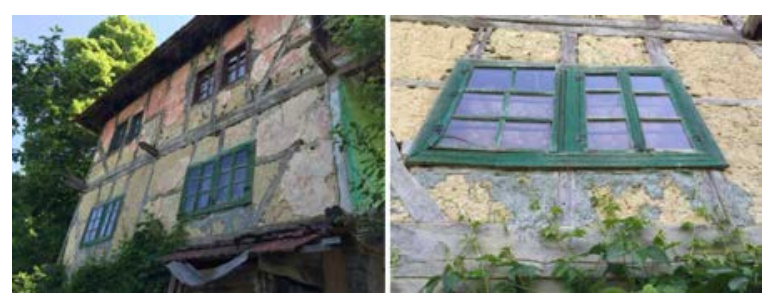

Figure 24. Double windows in rooms and chardaks

\section{Surface treatment and equipment of space}

All the wall surfaces of the house, both external and internal, were in its original solution plastered with clay mortar with the addition of straw and chaff (Figure 14, and Figure 24) and painted with lime milk. Over time, this plaster was devastated (and restored), with lime powder being added to the powder, mostly green (Figures 20, 21, 23, and Figure 25).

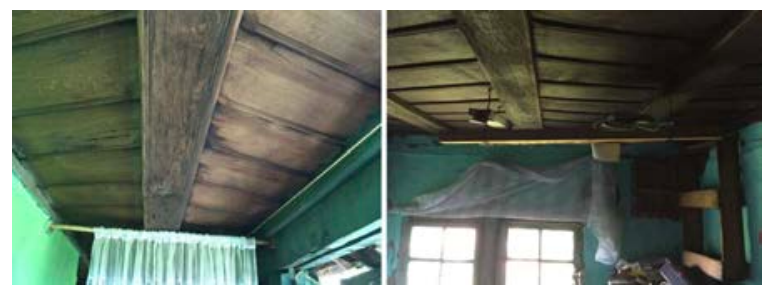

Figure 25: Left - divanhana ceiling; Right - ceiling in a small chardak

In all cases, the natural color of the wooden ceilings, which over time has been given a patina of chestnut color, has been preserved (Figure 18, Figure 25, and Figure 26).

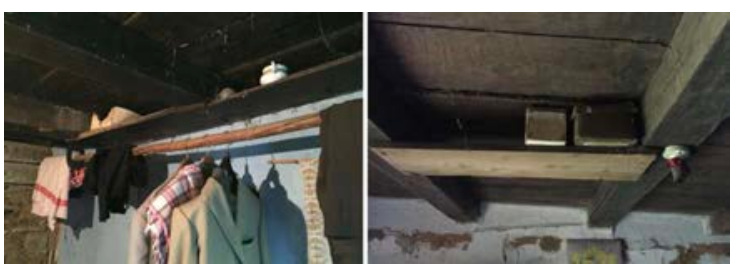

Figure 26: Archaic solutions of shelves ("rafa") and "open wardrobe" in the space of the chardak with the entrance from the gallery 
Many original equipment elements have been preserved in the interior of the house (Figure 10, Figure 26 , and Figure 27), but new elements have also been added (Figure 13).
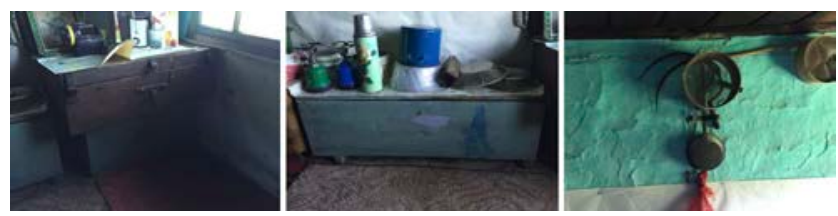

Figure 27: Left and center - authentic wooden chests for storing utensils and cutlery; Right - various utility items hung on the wall (in a small chardak)

Some traditional, extremely important items of equipment characteristic of a bosnian chardaklia house (such as a stone sink - "banjica") were thrown out of the house (Figure 28) without receiving adequate replacement.

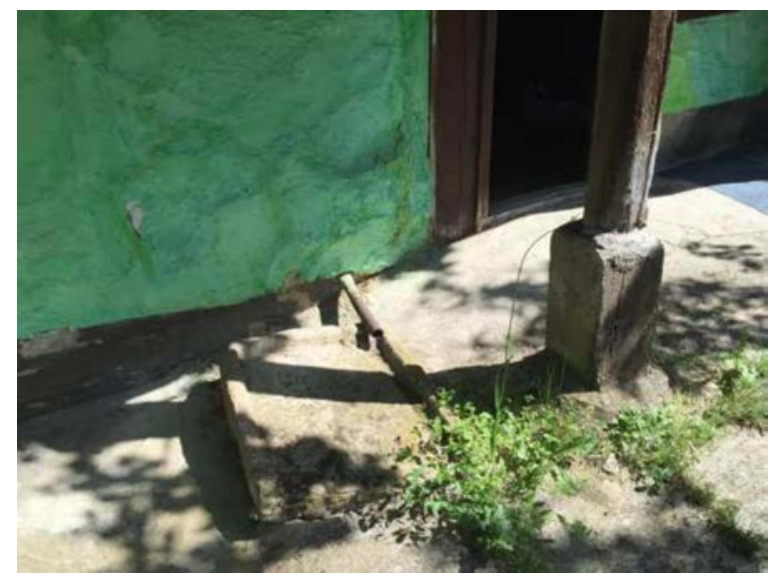

Figure 28: Bathtub - stone ("banjica") carving (originally placed in a room above the basement

The present condition and purpose of the house - Perspectives

The Dzider family's house in the Crnoc village near Kakanj, despite its reconstructions and renovations, has a preserved physical structure, which indicates the deep age of the building. Today's homeowners are in their late years and spend most of the year in their home in Kakanj, while they spend most of the summer in this home. The rich natural environment and the house that "carries the immense embodied energy of many generations who have lived there" is the best place where its present owners have a sense of "living today, together with their ancestors" (Figure 29).

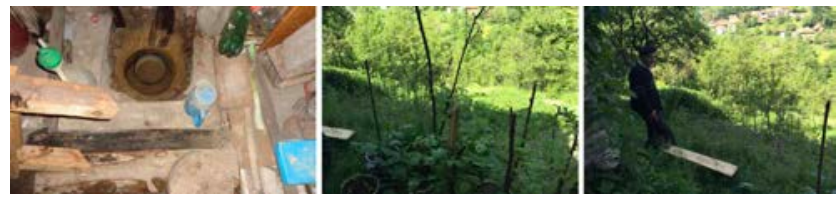

Figure 29: Left - a natural spring in the basement floor; Center and right - garden by the house
The undoubted architectural, historical and ambient values of this house should be preserved, first through its inclusion in the list of national monuments of Bosnia and Herzegovina, and then in the way of giving this object a function that will make it sustainable.

\section{Bioclimatic principles of the building}

The Dzider family's house in the Crnoc village near Kakanj is an example of the traditional bioclimatic architecture of Bosnia and Herzegovina. The principles of bioclimatic architecture are reflected in the following:

The building is located on a hilly terrain with southern exposure,

The basement is partly buried in the terrain, ensuring its storage function with a constant temperature (during all seasons),

In all elements of construction, natural materials used were taken on site, with a place in the building that corresponds to their best features,

The disposition of the object (horizontal and vertical plan) ensures the function of the space with an open hearth as a space that provides natural ventilation of the object (good cryptoclimate) and protection of all elements of the object made of wood against the aggressive action of insects and moisture,

Heating of individual rooms and chardakas is provided by furnaces, using wood as firewood, whereby the smoke generated in them is released into the central space ("dimluk"), which to some extent additionally warms the rooms ("heat recovery") and protects wooden elements of the physical structure of the object,

The spatial concept of the building allows it to be used as a single and two-family house (flexibility of architecture).

\section{References}

1. Hadrović A. Defining Architecrural Space on the Model of the Oriental Style City House in Bosnia and Herzegovina, Serbia, Montenegro, Kosovo and Macedonia. North Charleston, SC, USA: Booksurge, LLC; 2007.

2. Hadrović A. Bioclimatic Architecture, Searching for a Path to Heaven. SC, USA: Booksurge, LLC, North Charleston; 2008.

3. Hadrović A. Water and man in autoshthonous symbiosis in Bosnia and Herzegovina. Sarajevo: Avicena; 2014.

4. Hadrović A. Bosanska kuća čardaklija, Sarajevo. Sarajevo: Arhitektonski fakultet u Sarajevu; 2017. 